\title{
Autism screening at 18 months of age: a comparison of the Q-CHAT-10 and M-CHAT screeners
}

\author{
Raymond Sturner ${ }^{1,2^{*}} \mathbb{D}$, Barbara Howard ${ }^{1,3}$, Paul Bergmann ${ }^{3,4}$, Shana Attar ${ }^{3,6}$, Lydia Stewart-Artz ${ }^{2}$, Kerry Bet ${ }^{2,3}$, \\ Carrie Allison ${ }^{5}$ and Simon Baron-Cohen ${ }^{5}$
}

\begin{abstract}
Background: Autism screening is recommended at 18- and 24-month pediatric well visits. The Modified Checklist for Autism in Toddlers-Revised (M-CHAT-R) authors recommend a follow-up interview (M-CHAT-R/F) when positive. M-CHAT-R/F may be less accurate for 18-month-olds than 24-month-olds and accuracy for identification prior to two years is not known in samples that include children screening negative. Since autism symptoms may emerge gradually, ordinally scoring items based on the full range of response options, such as in the 10-item version of the Quantitative Checklist for Autism in Toddlers (Q-CHAT-10), might better capture autism signs than the dichotomous (i.e., yes/no) items in M-CHAT-R or the pass/fail scoring of Q-CHAT-10 items. The aims of this study were to determine and compare the accuracy of the M-CHAT-R/F and the Q-CHAT-10 and to describe the accuracy of the ordinally scored Q-CHAT-10 (Q-CHAT-10-O) for predicting autism in a sample of children who were screened at 18 months.
\end{abstract}

Methods: This is a community pediatrics validation study with screen positive $(n=167)$ and age- and practicematched screen negative children $(n=241)$ recruited for diagnostic evaluations completed prior to 2 years old. Clinical diagnosis of autism was based on results of in-person diagnostic autism evaluations by research reliable testers blind to screening results and using the Autism Diagnostic Observation Schedule-Second Edition (ADOS-2) Toddler Module and Mullen Scales of Early Learning (MSEL) per standard guidelines.

Results: While the M-CHAT-R/F had higher specificity and PPV compared to M-CHAT-R, Q-CHAT-10-O showed higher sensitivity than M-CHAT-R/F and Q-CHAT-10.

Limitations: Many parents declined participation and the sample is over-represented by higher educated parents. Results cannot be extended to older ages.

Conclusions: Limitations of the currently recommended two-stage M-CHAT-R/F at the 18-month visit include low sensitivity with minimal balancing benefit of improved PPV from the follow-up interview. Ordinal, rather than dichotomous, scoring of autism screening items appears to be beneficial at this age. The Q-CHAT-10-O with ordinal scoring shows advantages to M-CHAT-R/F with half the number of items, no requirement for a follow-up interview, and improved sensitivity. Yet, Q-CHAT-10-O sensitivity is less than M-CHAT-R (without follow-up) and specificity is less than the two-stage procedure. Such limitations are consistent with recognition that screening needs to recur beyond this age.

\footnotetext{
*Correspondence: rsturner@childhealthcare.org

1 Pediatrics, Johns Hopkins School of Medicine, Baltimore, USA

Full list of author information is available at the end of the article
} permits use, sharing, adaptation, distribution and reproduction in any medium or format, as long as you give appropriate credit to the original author(s) and the source, provide a link to the Creative Commons licence, and indicate if changes were made. The images or other third party material in this article are included in the article's Creative Commons licence, unless indicated otherwise in a credit line to the material. If material is not included in the article's Creative Commons licence and your intended use is not permitted by statutory regulation or exceeds the permitted use, you will need to obtain permission directly from the copyright holder. To view a copy of this licence, visit http://creativecommons.org/licenses/by/4.0/. The Creative Commons Public Domain Dedication waiver (http://creativeco mmons.org/publicdomain/zero/1.0/) applies to the data made available in this article, unless otherwise stated in a credit line to the data. 
Keywords: Autism screening, Developmental screening, M-CHAT, Q-CHAT

\section{Background}

Autism spectrum disorder (henceforth autism) is a prevalent and life-long condition, with a rate of 1 in 54 [1] by 8 years of age. A strong association between early evidence-based intervention with improved long-term outcomes for children with autism is one rationale for the recommendation by the American Academy of Pediatrics (AAP) and the Centers for Disease Control and Prevention $(\mathrm{CDC})$ for screening of autism in all children at 18 and 24 months [2-7]. However, the 2015 US Preventive Services Task Force (USPSTF) asserted that additional data are needed, in part due to a lack of adequate validation of the recommended tools in community samples [8].

The Checklist for Autism in Toddlers (CHAT), one of the first validated autism screening tests, showed initial promise for screening at 18-months with a high concurrent positive predictive value (PPV) [9]. However, at a 6-year follow-up, the 18-month CHAT had only identified $38 \%$ of children with an autism diagnosis [10]. The low sensitivity of the CHAT, and a desire to eliminate its child observation items, led to modifications of the screen, e.g., the Modified CHAT (M-CHAT) [11], that also added parent report items. Another modification, the Quantitative CHAT (Q-CHAT) [12], changed the dichotomous responses (yes/no) of the CHAT and M-CHAT to ordinal responses (how much/often), acknowledging autistic traits lie on a dimension [13].

While the M-CHAT is the most widely used autism screening test, it may not exceed the CHAT in longterm sensitivity, in part due to children that are not even detectable by diagnostic testing until a later age [14]. The revised M-CHAT (M-CHAT-R) authors now highly recommend use of a standardized follow-up clinicianadministered interview for most positive screens [15]. Of note, during validation studies, the follow-up interview was conducted by telephone as part of a "two-stage screener" process known as the M-CHAT-R/F, which increased PPV from 0.14 to 0.48 in a sample of M-CHAT$\mathrm{R}$ screen-positive children at 18- and 24-month wellchild visits [16]. In a high-risk sample of siblings of autistic individuals, the M-CHAT-R/F appeared to have good sensitivity (0.78) at 18 months. However, nearly one-fifth of those screening negative on the M-CHAT$\mathrm{R} / \mathrm{F}$ later were found to have an autism diagnosis [14]. However, the follow-up interview has an extremely low rate of utilization in primary care settings [17]. Even with the follow-up interview, the PPV was lower in younger toddlers compared to older toddlers in one community sample ( 0.28 vs. 0.61 , respectively), and similarly lower in another (0.36 vs. 0.69 , respectively) $[18,19]$. Results of samples with a high prevalence of autism, such as siblings of autistic children, cannot be generalized to typical community samples. Also, neither the M-CHAT-R nor the 10-item version of the Q-CHAT (Q-CHAT-10) has been studied in a representative community population of 18-month-olds with validation testing that includes both screen negatives and positives as needed to better estimate sensitivity. Furthermore, the different item response approaches of the ordinal version of the Q-CHAT-10 (Q-CHAT-10-O) and the dichotomous M-CHAT-R have never been directly compared.

Studies show that when the full cohort of toddlers screened by the M-CHAT is followed for several years, M-CHAT sensitivity and PPV are lower than in the concurrent validation studies of M-CHAT positive children because of the later emergence of autistic symptoms making diagnosis possible. In these follow-up studies predictive indices are lowest for the youngest toddlers. For example, a follow-up study in Norway showed that a positive M-CHAT (without follow-up) at 18 months identified only $34 \%$ of children with an autism diagnosis by 9 years old [20]. A recent report of screening with the M-CHAT at both the 18- and 24-month well-child visits, whose medical records were reviewed for autism diagnoses as outcomes at 4 to 8 years of age, reported a similar sensitivity of 0.35 for 18 -month screening; lower than a sensitivity of 0.49 at 24 months [21]. A sensitivity of 0.33 was found in a similar cohort follow-up reported as a combined 18- and 24-month sample [22]. In 2019, Guthrie, et al. found for the $41.2 \%$ of children whose score triggered the follow-up portion of the M-CHAT$\mathrm{R} / \mathrm{F}$, the PPV was also higher at the 24-month visit than when the same child was screened at 18 months (0.25 and 0.18 , respectively) [21].

An obstacle to estimates of prediction of autism diagnoses made years later is that some children may not have had any clinical manifestations at the earlier age and thus negative screens were ambiguous. In addition, a meta-analysis of reports shows that an average of $32 \%$ of toddlers, with an eventual diagnosis of autism, look typical at 18 months and then are reported at a later age to have regressed between 18- and 24-months [23]-one reason the AAP recommends rescreening at 24 months [6]. Additionally, data from prospective studies of highrisk infant siblings reveal that only $18 \%$ of children diagnosed with autism at 36 months were given that diagnosis at 18 months of age despite use of comprehensive 
diagnostic assessments. ${ }^{24}$ Prevalence is also reported as $30 \%$ higher at ages $8-12$ years than at $3-7$ years [25]. Children identified later with autism tend to have milder symptoms and higher cognitive functioning [26].

Strategies that are age-relevant and capture the natural emergence of autism are needed to address the screening challenges at 18 months. One approach may be sum scoring of ordinal scaled item responses such as those in the Q-CHAT [12]. The Q-CHAT-10 is particularly well suited for primary care because of its brevity, and reported sensitivity of 0.91 and specificity 0.89 in a case comparison study [27]. However, since data from community primary care populations are lacking, we cannot consider this to be a true estimate of sensitivity. Also, while the Q-CHAT-10 uses a five-point frequency response, its standard scoring instructions utilize a pass/fail cutpoint rather than ordinal scoring based on the full-scale range of the items. In this study, we compare the predictive utility of the M-CHAT-R, the M-CHAT-R/F, and the Q-CHAT-10 in a community sample that includes both toddlers who screen positive and screen negative on initial screening measures. An additional aim of this study was to compare the Q-CHAT-10 with its original pass/ fail scoring to an experimental ordinal scoring version we term Q-CHAT-10-O to better understand the contribution of ordinal scoring to accurate 18-month screening.

\section{Methods}

\section{Sampling and screening procedures}

Parents completed the M-CHAT-R before 18-month pediatric visits (16-20 months) via an online clinical process support system called CHADIS [28, 29]. M-CHAT-R positive screens prompted completion of M-CHAT-R/F by the PCP during or after the visit by phone, or by a research assistant using online prompts in CHADIS via a previously validated method [30]. The follow-up interview was completed for all M-CHAT-R positive parent reports except 23 which were not initiated $(n=17)$ or not completed $(n=6)$. In addition, parents completed the Q-CHAT-10 and Ages \& Stages QuestionnairesThird Edition (ASQ-3) [31]. The order of presentation of Q-CHAT-10 and M-CHAT-R to parents alternated with Q-CHAT-10 being administered before M-CHAT$\mathrm{R}$ one month and the reverse the following month. A total of 11,876 parents of children age 16-20 months from pediatric offices already using the CHADIS system in Maryland, Massachusetts, and North Carolina completed the M-CHAT-R and Q-CHAT-10 screens. These locations were chosen from a large national network of CHADIS users because of availability of home visiting diagnostic testers from the research team. The offices responded to a request for participation, and some of the offices received discounts in the use of the system. Pre-visit developmental and autism screening were routine in these offices and not based on any at risk estimation. Many of the pediatricians participated in web-based quality improvement activities approved by the American Board of Pediatrics for Maintenance of Certification professional credits (MOC-4) aimed at optimizing screening of all children. However, denominator data on numbers of well child visits were not available to document percentages of children whose parents may not have ever registered in the online system to complete screens. This study employed the version of the Q-CHAT-10 that has been recommended for clinical use by its authors. This version included pictures illustrating each of the items. Of 787 children with any positive screen result (Q-CHAT-10 or M-CHAT-R, even if follow-up was negative), 308 respective parents were contacted by phone or email for enrollment. Gender and age (within one month)-matched controls with both screens negative $(n=331)$ were then successfully contacted from the same practice or a practice with similar demographics in the same area. Children were excluded if their parents reported that they were exposed to English at home less than $50 \%$ of the time or if they were not yet walking or scooting as required to complete the ADOS-2 Toddler Module [32] for autism diagnostic testing. Figure 1 presents the sample flow from screening to formal assessment and diagnosis.

The study enrolled 469 children and lost 61 to attrition. The final sample includes 408 children with available data on key items and final autism case status determination. A total of 164 children were screen positives on M-CHAT-R (including $53 \mathrm{M}-\mathrm{CHAT}-\mathrm{R} / \mathrm{F}$ positives), and 39 were Q-CHAT-10 positive (of which 36 were also M-CHAT-R positive). There are a total of 241 who screened negative on both the M-CHAT-R and Q-CHAT-10. The initial screening component was deemed exempt by the IRB; parents of recruited children provided written consent and received a participation fee of $\$ 200$ without charge for the evaluation.

\section{Measures}

\section{Screens}

Modified Checklist for Autism in Toddlers, Revised With Follow-Up Interview (M-CHAT-R/F) $[11,15,16]$. The M-CHAT-R is a parent-report checklist with 20 yes/no response options. A follow-up interview (M-CHAT-R/F) is recommended for a positive M-CHAT-R screen when 3-7 items were failed. M-CHAT-R/F has been reported to have a PPV of 0.48 in a community sample of both 18and 24-month visits assessing only screen positive children [15].

Q-CHAT-10 and Q-CHAT-10-O. Quantitative Checklist for Autism in Toddlers (Q-CHAT) was developed to 


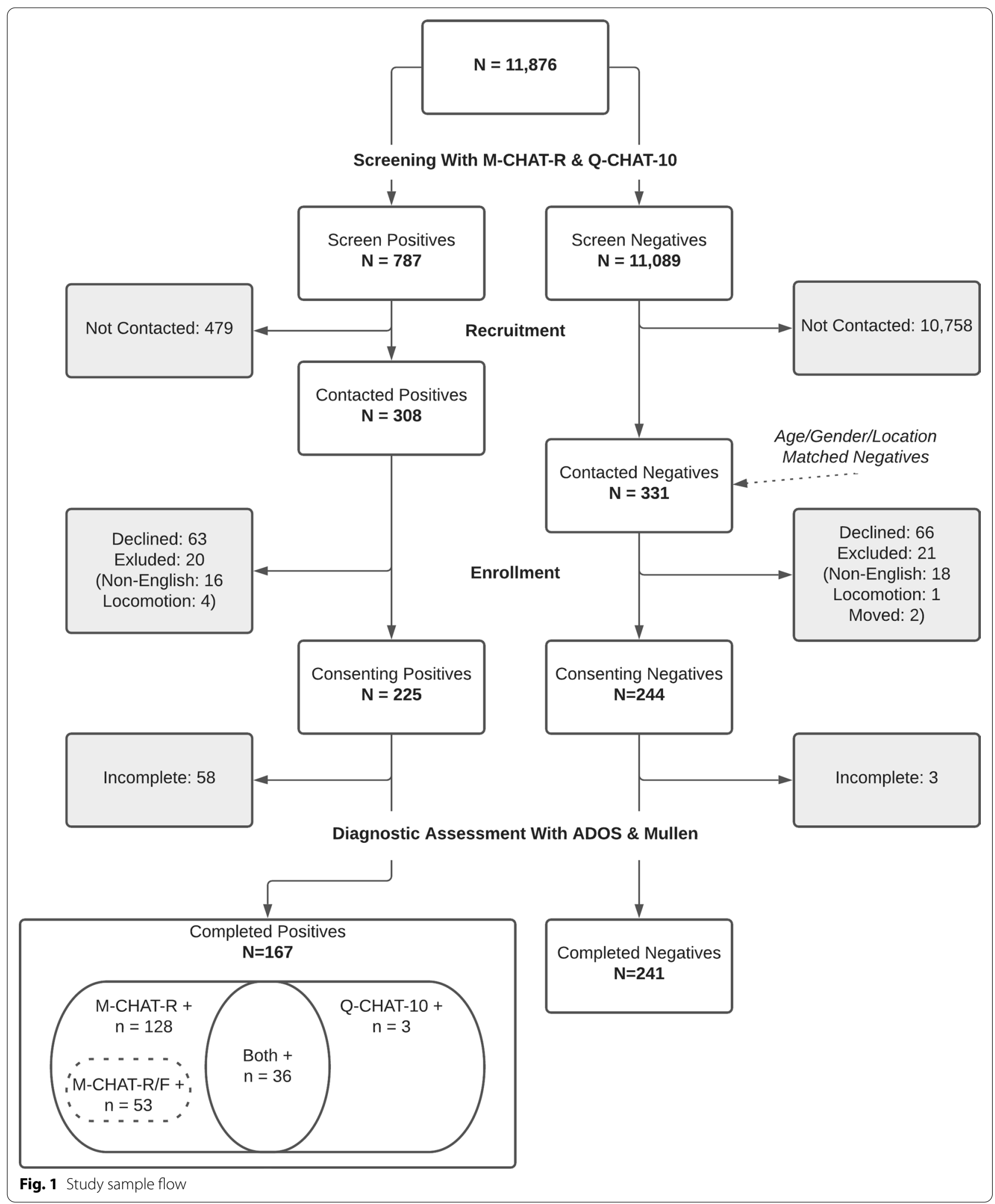


provide a range of response options for autism symptoms in toddlers which included 25 items [12]. A 10-item version (Q-CHAT-10) tested retrospectively on toddlers with an autism diagnosis compared to unselected toddlers reported sensitivity 0.91 and specificity 0.89 [27]. While the original Q-CHAT uses 5-point Likert scales of quantity or frequency, each item is still scored as a binary pass/fail.

\section{Diagnostic assessments}

Autism Diagnostic Observation Schedule, 2nd Ed. (ADOS-2) Toddler Module [32]. The ADOS, a semistructured behavior observation assessment of social and communication skills, was modified to assure accuracy for toddlers (ADOS-2 Toddler Module). The recommended score cutpoint for 12-21-month-olds yielded 0.91 sensitivity and 0.91 specificity for autism [32].

Mullen Scales of Early Learning (MSEL) [33]. MSEL is a standardized developmental test for children 3-69 months. An Early Learning Composite (ELC) is generated using scores from 4 of 5 subscales (Visual Reception, Expressive Language, Receptive Language and Fine Motor), providing a developmental quotient, which is used to determine the expected levels of communicative and social functioning.

\section{Diagnostic procedures}

All children completed in-person diagnostic autism evaluations using the ADOS-2 Toddler Module [32] and Mullen Scales of Early Learning (MSEL) [33]. Diagnostic testers were all experienced autism evaluators; three were certified as research reliable on the toddler module prior to the evaluations and one attained reliability through video review by a certified research reliable tester before finalized scoring. All diagnostic testers were blinded to screening results.

Results of the ADOS-2 and information from the MSEL, along with parental history focused on a review of current functioning, informed a clinical judgment of whether a child met criteria for autism based on the Diagnostic and Statistical Manual of Mental Disorders-5 (DSM-5) [34, 35]. Developmental disorder was defined by the typical criteria for early intervention services (score $>1-1 / 2$ SD below the mean on two or more subscales or $>2$ SD on a single subscale of the MSEL) [36].

\section{Results}

Respondents were primary caregivers, almost all mothers who tended to be well educated and privately insured (See Tables 1 and 2).

ADOS-2 \& MSEL scores are presented in Table 3. Mean t-scores on all scales of the MSEL for children determined to have autism diagnoses were significantly
Table 1 Patient demographics

\begin{tabular}{|c|c|c|}
\hline & $n$ & $\%$ \\
\hline Screening age (months) — [mean (SD)] & $18.02(0.53)$ & \\
\hline Diagnosis age (months) — [mean (SD)] & $20.49(1.86)$ & \\
\hline $\begin{array}{l}\text { Diagnosis age (months) ASD Screen } \\
\text { positive-[mean (SD)] }\end{array}$ & $19.98(1.50)$ & \\
\hline $\begin{array}{l}\text { Diagnosis age (months) ASD Screen } \\
\text { negative-[mean (SD)] }\end{array}$ & $20.59(1.91)$ & \\
\hline \multicolumn{3}{|l|}{ Sex } \\
\hline Female & 114 & $27.94 \%$ \\
\hline Male & 294 & $72.06 \%$ \\
\hline \multicolumn{3}{|l|}{ Race } \\
\hline Asian & 19 & $4.71 \%$ \\
\hline Black & 39 & $9.68 \%$ \\
\hline White & 281 & $69.73 \%$ \\
\hline Multiple & 58 & $14.39 \%$ \\
\hline Unknown & 6 & $1.49 \%$ \\
\hline \multicolumn{3}{|l|}{ Hispanic or Latino } \\
\hline No & 375 & $93.05 \%$ \\
\hline Yes & 27 & $6.70 \%$ \\
\hline \multicolumn{3}{|l|}{ Private Payer } \\
\hline Yes & 346 & $85.86 \%$ \\
\hline \multicolumn{3}{|l|}{ Public payer } \\
\hline Yes & 48 & $11.76 \%$ \\
\hline \multicolumn{3}{|l|}{ Other payer } \\
\hline Yes & 50 & $12.25 \%$ \\
\hline \multicolumn{3}{|l|}{ Household income } \\
\hline$<\$ 50,000$ & 18 & $6.57 \%$ \\
\hline$\$ 50,000-\$ 150,000$ & 132 & $48.18 \%$ \\
\hline$>=\$ 150,000$ & 124 & $45.26 \%$ \\
\hline
\end{tabular}

lower than for those without a diagnosis (See Additional file 1: Table S1).

Similarly, mean scores on the MSEL of children screening positive on any of the autism screens were significantly lower on all scales than for those screening negative (See Additional file 1: Tables S2-S5).

The demographic profile of children diagnosed with autism differed from those who were not found to have autism by being more likely to have a family income $<\$ 50,000$ and less likely to have private insurance (See Additional file 2: Table S1). The adult respondents (almost all parents) for children who were found to have an autism diagnosis were less likely to be married, and more likely to have a household income of $<\$ 50,000$ and not have a college degree (See Additional file 2: Table S6). There were no overall differences in being diagnosed with autism by child's race (See Additional file 2: Table S1). However, there were racial differences (of children and respondents) in the proportion of children screening positive on both the M-CHAT-R and M-CHAT-R/F, but not 
Table 2 Respondent demographics

\begin{tabular}{|c|c|c|}
\hline & $n$ & $\%$ \\
\hline \multicolumn{3}{|l|}{ Relationship to child } \\
\hline Mother & 374 & $91.67 \%$ \\
\hline Father & 31 & $7.60 \%$ \\
\hline Other primary & 3 & $0.74 \%$ \\
\hline Age- $-[$ mean (SD)] & $34.27(4.34)$ & \\
\hline \multicolumn{3}{|l|}{ Marital status } \\
\hline Married & 368 & $91.32 \%$ \\
\hline Separated & 4 & $0.99 \%$ \\
\hline Widowed & 1 & $0.25 \%$ \\
\hline Never married & 12 & $2.98 \%$ \\
\hline Living with partner & 15 & $3.72 \%$ \\
\hline \multicolumn{3}{|l|}{ Race } \\
\hline Asian & 29 & $7.11 \%$ \\
\hline Black & 37 & $9.07 \%$ \\
\hline White & 314 & $76.96 \%$ \\
\hline Multiple & 21 & $5.15 \%$ \\
\hline Unknown/missing & 7 & $1.72 \%$ \\
\hline \multicolumn{3}{|l|}{ Hispanic or latino } \\
\hline No & 379 & $94.04 \%$ \\
\hline Yes & 23 & $5.71 \%$ \\
\hline \multicolumn{3}{|l|}{ Bachelor degree } \\
\hline No & 75 & $18.61 \%$ \\
\hline Yes & 328 & $81.39 \%$ \\
\hline \multicolumn{3}{|l|}{ Household income } \\
\hline$<\$ 50,000$ & 18 & $6.57 \%$ \\
\hline$\$ 50,000-\$ 150,000$ & 132 & $48.18 \%$ \\
\hline$>=\$ 150,000$ & 124 & $45.26 \%$ \\
\hline
\end{tabular}

on the Q-CHAT-10 or Q-CHAT-10-O (See Additional file 2: Tables S2-S11). For the M-CHAT-R, M-CHAT-R/F and Q-CHAT-10, there were more positives among children with family incomes $<\$ 50,000$; the Q-CHAT-10-O did not show this difference (See Additional file 2: Tables S1-S10).

Two one-sided tests for equivalence (TOST) were conducted to compare sensitivity, specificity, PPV and NPV between screening approaches [37, 38]. In all TOST analyses, a 5 -point difference $(\delta=0.05)$ in proportions was considered clinically significant. Each application of TOST utilizes two separate tests of proportions with $\alpha=0.05$ to arrive at one of four determinations (D: Relevant Difference [statistically \& clinically significant], E: Equivalence [statistically \& clinically significant], T: Trivial Difference [statistically significant, but clinically insignificant], I: Indeterminate Result [underpowered test for the data]).

The M-CHAT-R/F follow-up interview procedure increased PPV and specificity over the M-CHAT-R but decreased sensitivity (See Table 4; See also Additional
Table 3 Diagnostic score results

\begin{tabular}{|c|c|c|c|c|c|}
\hline & $n$ & Mean & SD & Min & Max \\
\hline \multicolumn{6}{|l|}{ ADOS scores (overall) } \\
\hline Social affect total & 406 & 5.0 & 4.9 & 0 & 20 \\
\hline Restricted/repetitive behavior total & 405 & 1.7 & 1.9 & 0 & 8 \\
\hline Overall total (SA+RRB) & 405 & 6.6 & 6.1 & 0 & 24 \\
\hline Range of concerns & 401 & 1.4 & 0.8 & 1 & 3 \\
\hline \multicolumn{6}{|l|}{ ADOS scores (ASD negative) } \\
\hline Social affect total & 344 & 3.5 & 3.2 & 0 & 14 \\
\hline Restricted/repetitive behavior total & 343 & 1.2 & 1.5 & 0 & 6 \\
\hline Overall total (SA + RRB) & 343 & 4.7 & 4.0 & 0 & 17 \\
\hline \multicolumn{6}{|l|}{ ADOS scores (ASD positive) } \\
\hline Social affect total & 62 & 13.4 & 3.6 & 6 & 20 \\
\hline Restricted/repetitive behavior total & 62 & 4.1 & 1.9 & 1 & 8 \\
\hline Overall total (SA + RRB) & 62 & 17.5 & 3.7 & 9 & 24 \\
\hline \multicolumn{6}{|l|}{ MSEL T-scores } \\
\hline Gross motor & 405 & 50.8 & 9.6 & 20 & 80 \\
\hline Visual reception & 404 & 54.5 & 12.0 & 20 & 80 \\
\hline Fine motor & 405 & 50.6 & 9.2 & 20 & 80 \\
\hline Receptive language & 404 & 50.3 & 9.2 & 20 & 80 \\
\hline Expressive language & 405 & 45.9 & 13.7 & 20 & 80 \\
\hline
\end{tabular}

file 3: Tables S4a-S4d for an alternative detailed view). Six of the 10 children with M-CHAT-R scores $>=8$ were diagnosed with autism. Since these high scores are unusual, we chose to explore this decision rule by performing a follow-up interview with these 10 even though the M-CHAT-R scoring indicates that they should be screened positive without relying on the interview. This follow-up interview for these 10 children was falsely negative for 3 of the 6 with an autism diagnosis. Q-CHAT-10 with standard scoring had higher PPV and specificity compared with both M-CHAT-R and M-CHATR/F. However, Q-CHAT-10 had lower sensitivity than M-CHAT-R.

Another aim of this study was to explore the potential of ordinally scoring the Q-CHAT-10 by summing the full ordinal range of item responses rather than their dichotomized transformations. In this report ordinal re-scoring of the Q-CHAT-10 is denoted as Q-CHAT-10-O.

Ordinal scoring resulted in an area under the ROC curve (AUC) of 0.75 [0.71, 0.79] and a cutpoint of $>=12$ that optimized the balance of sensitivity (0.63) versus specificity (0.79) via Youden's J (0.42). Youden's J ( $\mathrm{J}=$ sensitivity + specificity -1$)$ summarizes the performance of a dichotomous diagnostic test [39]. The index ranges from 0 to 1 . A value of one indicates the test is perfect (no false positives or false negatives). In receiver operating characteristic (ROC) analyses, $\mathrm{J}$ is defined for each point on the ROC curve, and the maximum value of the index is used to select the optimum 
Table 4 ASD screening performance comparisons

\begin{tabular}{llllll}
\hline Row & Screen & Sensitivity & Specificity & PPV & NPV \\
\hline 1 & M-CHAT-R & $0.73[0.61,0.82]$ & $0.66[0.61,0.71]$ & $0.28[0.22,0.35]$ & $0.93[0.89,0.96]$ \\
& $n=408$ & $2 \mathrm{D}|3 \mathrm{D}| 4 \mathrm{D}$ & $2 \mathrm{D}|3 \mathrm{D}| 4 \mathrm{D}$ & $2 \mathrm{D}|3 \mathrm{D}| 4 \mathrm{D}$ & 2|| $3 \mathrm{D} \mid 4 \mathrm{E}$ \\
2 & M-CHAT-R/F & $0.36[0.24,0.49]$ & $0.89[0.85,0.92]$ & $0.36[0.24,0.49]$ & $0.89[0.85,0.92]$ \\
3 & $n=368$ & $1 \mathrm{D}|3| \mid 4 \mathrm{D}$ & $1 \mathrm{D}|3 \mathrm{D}| 4 \mathrm{D}$ & $1 \mathrm{D}|3 \mathrm{D}| 4 \mid$ & 1|| $3 \mathrm{E}|4|$ \\
3 & Q-CHAT-10 & $0.34[0.23,0.46]$ & $0.95[0.92,0.97]$ & $0.54[0.39,0.68]$ & $0.89[0.85,0.92]$ \\
4 & $n=406$ & $1 \mathrm{D}|2| \mid 4 \mathrm{D}$ & $1 \mathrm{D}|2 \mathrm{D}| 4 \mathrm{D}$ & $1 \mathrm{D}|2 \mathrm{D}| 4 \mathrm{D}$ & $1 \mathrm{D}|2 \mathrm{E}| 4 \mid$ \\
& Q-CHAT-10-O & $0.63[0.50,0.74]$ & $0.79[0.74,0.83]$ & $0.35[0.27,0.44]$ & $0.92[0.89,0.95]$ \\
& $n=406$ & $1 \mathrm{D}|2 \mathrm{D}| 3 \mathrm{D}$ & $1 \mathrm{D}|2 \mathrm{D}| 3 \mathrm{D}$ & $1 \mathrm{D}|2| \mid 3 \mathrm{D}$ & $1 \mathrm{E}|2||3|$ \\
\hline
\end{tabular}

cutpoint when a test produces a numeric rather than dichotomous result [40]. The cutpoint $>=12$ was applied to Q-CHAT-10-O for comparisons of screening performance.

The M-CHAT-R/F is a two-stage procedure with different cutpoints for each stage. AUC analysis is not appropriate for M-CHAT-R/F given M-CHAT-R/F produces dichotomous results that are determined using discontinuous methods. However, it should be noted that the study's chosen M-CHAT-R/F cutpoint of $>=2$ is consistent with the recommended second stage cutpoint after verification of the parent's responses following an M-CHAT- $R$ screen positive based on a $>=3$ cutpoint.

Q-CHAT-10-O had higher specificity and PPV than M-CHAT-R with substantially less compromise in sensitivity than M-CHAT-R/F or Q-CHAT-10. However, Q-CHAT-10-O's specificity was lower than M-CHAT$\mathrm{R} / \mathrm{F}$ and Q-CHAT-10.

Cronbach's alpha for Q-CHAT-10 as a test scale was 0.55 , and for Q-CHAT-10-O was 0.76. As a two-stage procedure the M-CHAT-R/F is not used in the conventional test theory manner of summing individual item responses/results. Therefore, internal consistency estimates are not appropriate and would be misleading.

\section{Discussion}

When toddlers are screened in primary care at the 18-month visit, one cannot assume that children screening negative on the M-CHAT-R/F but positive on the M-CHAT-R or Q-CHAT screens are unlikely to have an autism diagnosis due to low the sensitivity of the M-CHAT-R/F. In fact, most children confirmed by diagnostic evaluations as having autism in this sample had negative M-CHAT-R/F follow-up interviews. Additionally, two community screening follow-up studies showed most children diagnosed with autism $2-1 / 2$ to 7 years later had screened negative on the M-CHAT screen when 18 months old $[24,25]$. However, as noted earlier, autism has been recognized as having a heterogenous trajectory of symptoms including many with the late onset of diagnosable symptoms [23, 24]. Unlike for typical clinical care when diagnostic testing is often delayed due to waiting lists or other issues, in this study we were often able to accommodate families through home testing and thereby completed all diagnostic testing prior to age two. The sensitivity estimates therefore should be more representative of children prior to the increases in prevalence expected by the natural history of this condition. The sensitivity estimate for the M-CHAT-R in this study was higher than in prior long-term outcome studies cited but lower than estimated in prior concurrent validation samples without screen negatives [15, 21-23]. This finding is in line with prospective data showing that most children diagnosed with autism at age three were not detectable at 18 months even with gold standard diagnostic testing [24]. It is also a response to recent commentary recommending that validity studies of autism screening tests focus on comparisons "against the gold standard assessment at that target age." [41]

M-CHAT-R scoring without the follow-up was more sensitive to autism diagnoses than the recommended two-stage procedure (M-CHAT-R/F) but at the cost of lower PPV, consistent with prior M-CHAT-R studies [15]. Also consistent with prior studies at 18 months versus 24 months, inclusion of the follow-up interview still resulted in relatively low PPV [21, 22]. It should be noted that those M-CHAT-R/F estimates are limited by omission of the follow-up interview in some M-CHAT-R positive cases [21,22]. Even with access to electronic support for completing the M-CHAT-R/F, the follow-up interview was inadvertently omitted $14 \%$ of the time in the current study and $59 \%$ of the time in a previous followup study when a similar application of electronic decision support was available [21]. On the other hand, studies of practices without any decision supports reveal that the follow-up interview is very rarely completed [17]. This study's results are consistent with the recommendation to omit the follow-up interview in cases with M-CHAT-R scores $>=8$, rather than risking false negatives. 
In a prior study, prediction of an autism diagnosis when pediatricians used online decision support for conducting the follow-up interview was equivalent to when used by autism center personnel [30]. That study also provided similar results at 24 months as in prior M-CHAT-R studies. This suggests that the differing results by age were not due to inaccurate follow-up interviews. There are a number of possible explanations for differing results across this age range that have potential implications for autism screening test development. In another prior study we found that when older toddlers $(20+$ months $)$ were compared with younger ( $<20$ months), the younger toddlers had higher rates of item failure, with items that reflected more advanced developmental milestones having the highest failure rates [42], suggesting that autism screening tests may need age-related scoring cutpoints. Prospective studies suggest that autism symptoms emerge gradually [13], which may be reflected in a lower number of endorsed autism-specific items in younger children. These studies suggest that the early toddler age range studied here is dynamic in both the emergence of typical developmental milestones and the absence of them characterizing the autism syndrome. In the current context, "emergence" means the milestone may not be fully in place to be acknowledged by a yes or no response. Q-CHAT-10, with its ordinally scaled items, may better capture the nuanced manifestations of emerging developmental milestones.

Q-CHAT-10 with standard scoring showed greater specificity and PPV over M-CHAT-R and greater sensitivity than M-CHAT-R/F. While the Q-CHAT-10 is predicated on a "quantitative" range of responses, this study reveals that its simplified dichotomous scoring potentially compromises sensitivity relative to the ordinally scored Q-CHAT-10-O (0.47 vs. 0.66, respectively). While low resource settings might favor screens such as the Q-CHAT-10 with high specificity and low sensitivity, missing most of the affected individuals, this is not consistent with the public health goal of identifying all affected individuals in a population. Additional significant advantages of Q-CHAT-10-O over M-CHAT$R$ are that it requires half the number of items, and does not require a follow-up clinician interview. The Q-CHAT-10 and Q-CHAT-10-O, unlike the M-CHAT-R and M-CHAT-R/F, did not show significant overall differences in screen results across race of child or respondent. The lack of a significant difference across race was also true for autism diagnosis. The Q-CHAT-10-O was the only screen not showing a difference by family income. This may suggest that the format of graded responses and pictorial images may be less culturally biased. However, larger numbers of racial and economic subgroups are needed to confirm these impressions.

The limitations of the M-CHAT-R and its follow-up interview identified in this study are not an argument against the potential of parent-reported screening for autism in the 18-month well visit age group. Rather, they indicate a need for parent-reported tools that provide a more nuanced screening for emergent signs of autism in this age group. Simplified scoring of the M-CHAT-R with yes/no responses and of the Q-CHAT-10 with dichotomous cut points of ordinally scaled items runs counter to this goal. Such reductive techniques become less compelling as the availability of computing resources increases. Further, the simple sum score of Q-CHAT-10-O items may be as easy as the original scoring algorithm of Q-CHAT-10, and results in a measure with greater internal consistency.

This study represents one of the largest groups of toddlers with autism diagnostic testing before age two from a community sample. The sample of children could not feasibly include all children screened thus precluding an absolute estimate of screening sensitivity. We therefore presented the typical test performance estimates to allow comparison to other studies.

\section{Conclusions}

This study reveals lower sensitivity to an autism diagnosis for the recommended two-stage M-CHAT-R/F than has been previously reported. There are two likely reasons for this discrepancy. First, this study differed from prior reports by obtaining diagnostic testing for children who screened negative on both autism screens as well as those who screened positive on at least one. Some of the screened negative children turned out to have autism diagnoses which would have been overlooked if we had not sampled them. Additionally, prior M-CHAT-R/F results have combined both 18- and 24-month well visit data, while our sample was exclusively collected at the 18-month visit. Prior studies have suggested less accuracy of screens at 18 months than at 24 months. Since the outcome comparison in this study involved timely completion of diagnostic testing, it provides a better estimate of what is possible when using these screens at the earliest currently recommended age for screening, occurring prior to some developmental shifts in the natural history of this condition [23-25]. The higher sensitivity of the M-CHAT-R compared to M-CHAT$\mathrm{R} / \mathrm{F}$ occurred with less balancing benefit of increase in PPV as in studies including both 18- and 24-month visits. However, when the Q-CHAT-10 is scored using the full range of responses for each item (Q-CHAT-10-O), there are screening performance improvements over both the M-CHAT-R and M-CHAT-R/F. In addition, 
the Q-CHAT-10-O requires half the number of items, and has no requirement for a follow-up interview. The Q-CHAT-10-O is freely available from its authors and can be administered and scored without a computer. The Q-CHAT-10-O can therefore be recommended for autism screening at 18 months. As with all these parentreported autism screens, this solution falls below generally accepted standards for screening performance [43] with a relatively low PPV, meaning most children screening positive will not be confirmed by diagnostic testing as having autism. While eliminating the follow-up interview is an important practical efficiency, it is possible that future research might identify follow-up questions for the Q-CHAT-10-O that might improve the limited positive predictive value which remains as a challenge at the 18-month visit. However, children with false positive screens for autism have been shown to have a high rate of "developmental concerns" [15]. When making an autism referral for young toddlers, clinicians might also consider the possibility that the child has a developmental problem other than autism and could thereby benefit from an evaluation even if the result is not an autism diagnosis. We intend to report separately on whether toddler autism screening can be enhanced by combining data from autism and developmental screeners. We will also explore possible clinical utility of false positive autism screen results for identifying other developmental problems as suggested by the M-CHAT-R authors [15]. Another strategy to consider is one of tracking and rescreening after 20 months, when M-CHAT-R/F screen results appear to be more accurate [19]. This approach may delay beginning important early intervention, however. Further research is needed for greater accuracy of screening at the 18-month visit, possibly including greater sensitivity to language outcomes not seen in any of the screens reported here. Our group is developing a screening solution involving promising parent report adaptive computer-based strategies utilizing language items and more fully integrating autism screening with screening for developmental delay [19, 44]. In a separate study we have shown that no screen at any age group identifies all or even most autism cases suggesting that autism screening should be conducted continuously at different ages during childhood, adolescence, and adulthood [45]. Digital behavioral measures, e.g., visual gaze, may also hold promise when and if they become practical and validated in primary care settings [46].

\section{Limitations}

The sample in this study is not fully representative of the population of interest. Many contacted parents declined participation, more so in the screened negative group than in the screened positive group; parent participants were more highly educated than national rates; and children exposed to English less than fifty percent of the time were excluded. The Q-CHAT-10-O derives its score from the ordinal responses to the standard Q-CHAT-10 used in this study. It is possible that if the Q-CHAT-10-O had been used as the screen for the primary sample, some children may have screened positive and been more likely to have been recruited to the final sample. It should be noted that autism diagnoses were made without a standard caregiver report tool such as the Autism Diagnostic Interview-Revised (ADI-R) Algorithms for Toddlers and Young Preschoolers based on opinion that such data tends to be less accurate in young toddler samples identified by screening rather than parent concern [47]. However, the diagnostic results may have been different had such a tool been used. The version of the Q-CHAT-10 used in this study included illustrations of items as suggested by the authors, with unknown impact compared to the original. Results from these studies of 16-20-montholds cannot be extended to older ages.

\section{Abbreviations \\ PCP: Primary care provider; M-CHAT-R: Modified checklist for Autism in Toddlers-Revised; M-CHAT-R/F: Modified Checklist for Autism in Toddlers Follow-up Interview; ADOS-2: The Autism Diagnostic Observation Schedule, Second Edition; MSEL: Mullen Scales of Early Learning; ROC: Receiver operat- ing characteristics; Q-CHAT-10: Quantitative Checklist for Autism in Tod- dlers-10 item version; Q-CHAT-10-O: Q-CHAT-10 scored through full range of ordinal items; AUC: Area under the curve; CHADIS: Comprehensive Health And Decision Information System; PPV: Positive predictive value; AAP: American Academy of Pediatrics; CDC: Centers for Disease Control and Prevention.}

\section{Supplementary Information}

The online version contains supplementary material available at https://doi. org/10.1186/s13229-021-00480-4.

Additional file 1. Supplementary tables: Outcomes by Screening Results. Additional file 2. Supplementary tables: Patient \& Respondent Demographics by Screening Result.

Additional file 3. Supplementary tables: Autism Screening Performance Comparisons.

\section{Acknowledgements}

Research reported in this publication was supported by the National Institute of Mental Health of the National Institutes of Health Award Number R44MH085399. The content is solely the responsibility of the authors and does not necessarily represent the views of the National Institutes of Health. The participating primary care pediatricians and their office staffs are acknowledged for their cooperation during the project and continuing implementation. We acknowledge testers including Ruth Williams, MA, Katherine Campe, MS, Jaime Allison, MEd, Margaret DeRamus, MS, and Tiffany Garner, PsyD with Trellis Services. We acknowledge Linda Lee who created illustrations for Q-CHAT items.

\section{Authors' contributions}

Raymond Sturner and Barbara Howard conceptualized, designed, and oversaw data collection during the study, drafted the initial manuscript, and approved the final manuscript as submitted. Lydia Stewart-Artz and Kerry Bet 
managed data collection and data entry, coordinated with offices, reviewed the manuscript and approved the final manuscript as submitted. Shana Attar performed autism and developmental evaluations, entered autism diagnostic conclusions, helped prepare the data for analysis, reviewed the manuscript and approved the final manuscript as submitted. Paul Bergmann helped design the project, carried out the analyses, reviewed and revised the manuscript, and approved the final manuscript as submitted. Simon Baron-Cohen and Carrie Allison conceptualized and assisted in design, reviewed and revised the manuscript, and approved the final manuscript as submitted. All authors approved the final manuscript as submitted and agree to be accountable for all aspects of the work.

\section{Funding}

All phases of this study were supported by NIMH grant no. R44MH085399. SBC received funding from the Wellcome Trust 214322 ZZ18\Z. For the purpose of Open Access, the author has applied a CC BY public copyright licence to any Author Accepted Manuscript version arising from this submission. Further to this SBC received funding from Innovative Medicines Initiative 2 Joint Undertaking (JU) under grant agreement No 777394. The JU receives support from the European Union's Horizon 2020 research and innovation programme and EFPIA and AUTISM SPEAKS, Autistica, SFARI. SBC also received funding from the Autism Research Trust, Autistica, the MRC and the NIHR Cambridge Biomedical Research Centre. The research was supported by the National Institute for Health Research (NIHR) Collaboration for Leadership in Applied Health Research and Care East of England at Cambridgeshire and Peterborough NHS Foundation Trust. The views expressed are those of the author(s) and not necessarily those of the NHS, NIHR or Department of Health and Social Care.

\section{Availability of data and materials}

The dataset used and analyzed during the current study is available from the corresponding author on reasonable request. Data is available from the corresponding author for reasonable requests.

\section{Declarations}

\section{Ethics approval and consent to participate}

Ethics approval for this study was obtained from the Medstar Health Research Institute Office of Research (Reference number 2014-069).

\section{Consent for Publication}

Not applicable.

\section{Competing interests}

This study was conducted by the Center for Promotion of Child Development through Primary Care and its for-profit subsidiary, CHADIS, Inc. CHADIS, the web-tool used in the study was developed by Dr. Sturner and his spouse, Dr. Howard. Dr. Sturner is Director of the Center and Dr. Howard is President of CHADIS, Inc. Both are members of the Board of Directors of Center and are paid employees or consultants to both entities. The other authors have indicated they have no financial relationships relevant to this article to disclose.

\section{Author details}

${ }^{1}$ Pediatrics, Johns Hopkins School of Medicine, Baltimore, USA. ${ }^{2}$ Center for Promotion of Child Development Through Primary Care, Baltimore, MD, USA. ${ }^{3}$ CHADIS, Inc., 6017 Altamont Place, Baltimore, MD, USA. ${ }^{4}$ Foresight Logic, Inc., St. Paul, MN, USA. ${ }^{5}$ Autism Research Centre, Department of Psychiatry, University of Cambridge, Cambridge, UK. ${ }^{6}$ University of Washington, Seattle, WA, USA.

Received: 23 March 2021 Accepted: 7 December 2021

Published online: 03 January 2022

\section{References}

1. Maenner, M.J., Kelly A.S., Jon B., EdS1, Anita W., Mary P., Monica DiRienzo, et al. Prevalence of autism spectrum disorder among children aged 8 years-autism and developmental disabilities monitoring network, 11 Sites, United States, 2016. In: MMWR. Surveillance Summaries 69, no. 4 (March 27, 2020), pp. 1-12. https://doi.org/10.15585/mmwr.ss6904a1
2. National Research Council. Educating children with autism. Washington: National Academies Press; 2001.

3. Howlin P, Magiati I, Charman T. Systematic review of early intensive behavioral interventions for children with autism. Am J Intellect Dev Disabil. 2009;114(1):23-41.

4. Dawson, G., Rogers, S., Munson, J., Milani Smith, Jamie Winter, J., Greenson, J., Donaldson, A., Varley, J., Randomized, controlled trial of an intervention for toddlers with autism: The early start denver model. Pediatrics. 2010; 125(1)

5. Warren Z, McPheeters ML, Sathe N, Foss-Feig JH, Glasser A, Veenstra-Vanderweele J. A systematic review of early intensive intervention for autism spectrum disorders. Pediatrics. 2011;127(5):e1303-11. https://doi.org/10. 1542/peds.2011-0426.

6. American Academy of Pediatrics. Identifying infants and young children with developmental disorders in the medical home: an algorithm for developmental surveillance and screening. Pediatrics. 2006;118(1):405-20.

7. https://www.cdc.gov/ncbddd/autism/screening.html Accessed $1 / 17 / 2021$.

8. Siu, A. L., and The US Preventive Services Task Force (USPSTF). Screening for autism spectrum disorder in young children US preventive services task force recommendation statement. JAMA J Am Med Assoc. 2016;315(7), 691-696. https://doi.org/10.1001/jama.2016.0018.

9. Baron-Cohen S, Allen J, Giliberg C. Can autism be detected at 18 months? The needle, the haystack, and the CHAT. Br J Psychiatry. 1992;161:839-43.

10. Baron-Cohen S, Cox A, Baird G, et al. Psychological markers in the detection of autism in infancy in a large population. Br J Psychiatry. 1996;168(2):158-63.

11. Robins DL, Fein D, Barton ML, Green JA. The modified checklist for autism in toddlers: an initial study investigating the early detection of autism and pervasive developmental disorders. J Autism Dev Disord. 2001:31(2):13144. https://doi.org/10.1177/1362361308094502.

12. Allison C, Baron-Cohen S, Wheelwright S, et al. The Q-CHAT (Quantitative CHecklist for Autism in Toddlers): a normally distributed quantitative measure of autistic traits at 18-24 months of age: preliminary report. J Autism Dev Disord. 2008;38(8):1414-25.

13. Ozonoff S, Heung K, Byrd R, Hansen R, Hertz-Picciotto I. The onset of autism: patterns of symptom emergence in the first years of life. Autism Res. 2008;1(6):320-8. https://doi.org/10.1002/aur.53.

14. Weitlauf AS, Vehorn AC, Stone WL, Fein D, Warren ZE. Using the M-CHAT$\mathrm{R} / \mathrm{F}$ to identify developmental concerns in a high-risk 18-month-old sibling sample. J Dev Behav Pediatr. 2015;36(7):497-502. https://doi.org/ 10.1097/DBP.0000000000000194.

15. Robins DL, Casagrande K, Barton M, Chen CMA, Dumont-Mathieu T, Fein D. Validation of the modified checklist for autism in toddlers, revised with follow-up (M-CHAT-R/F). Pediatrics. 2014, 133(1):37-45. https://doi.org/10. 1542/peds.2013-1813.

16. Kleinman JM, Robins DL, Ventola PE, Pandey J, Boorstein HC, Esser EL, Barton M. The modified checklist for autism in toddlers: a follow-up study investigating the early detection of autism spectrum disorders. J Autism Dev Disord. 2008;38(5):827-39. https://doi.org/10.1007/ s10803-007-0450-9.

17. Swanson A R Warren Z E, Stone W L, Vehorn A C, Dohrmann E, Humberd Q. The diagnosis of autism in community pediatric settings: does advanced training facilitate practice change? Autism. 2014; 18(5):555561. https://doi.org/10.1177/1362361313481507.

18. Pandey J, Verbalis A, Robins D L, Boorstein H, Klin A, Babitz T, Fein D. Screening for autism in older and younger toddlers with the modified checklist for autism in toddlers. Autism Int J Res Pract. 2008;12(5):513535. https://doi.org/10.1177/1362361308094503.

19. Sturner R, Howard BJ, Bergmann P, Morrel TL, Walton K. Marks D. Accurate autism screening at the 18-month well-child visit requires different strategies than at 24 months J Autism Relat. Disord. 2017; 1-15. https://doi.org/ 10.1007/s10803-017-3231-0.

20. Stenberg N, Bresnahan M, Gunnes N, Hirtz D, Hornig M, Lie KK, Schjlberg S. Identifying children with autism spectrum disorder at 18 months in a general population sample. Paediatr Perinat Epidemiol. 2014;28(3):25562. https://doi.org/10.1111/ppe.12114.

21. Guthrie W, Wallis K, Bennett A, et al. Accuracy of autism screening in a large pediatric network. Pediatrics. 2019;144(4). 
22. Carbone PS, Campbell K, Wilkes J, Stoddard GJ, Huynh K, Young PC, Gabrielsen TP. Primary care autism screening and later autism diagnosis. Pediatrics. 2020;146(2):e20192314. https://doi.org/10.1542/peds.2019-2314

23. Barger BD, Campbell JM, McDonough JD. Prevalence and onset of regression within autism spectrum disorders: a meta-analytic review. J Autism Dev Disord. 2013;43(4):817-28. https://doi.org/10.1007/ s10803-012-1621-X.

24. Zwaigenbaum L, Bryson SE, Brian J, et al. Stability of diagnostic assessment for autism spectrum disorder between 18 and 36 months in a high-risk cohort. Autism Res. 2016;9(7):790-800.

25. Zablotsky B, Black LI, Blumberg SJ. Estimated prevalence of children with diagnosed developmental disabilities in the United States, 2014-2016. NCHS Data Brief, No. 291. Hyattsville, MD: CDC, National Center for Health Statistics; 2017;291:1-8.

26. Zwaigenbaum L, Duku E, Fombonne E, et al. Developmental functioning and symptom severity influence age of diagnosis in Canadian preschool children with autism. Paediatr Child Health. 2019;24(1):e57-65.

27. Allison C, Auyeung B, Baron-Cohen S. Toward brief "red flags" for autism screening: THE short autism spectrum quotient and the short quantitative checklist in 1,000 cases and 3,000 controls. J Am Acad Child Adolesc Psychiatry. 2012;51(2):202-12.

28. CHADIS (Comprehensive Health and Decision Information System). http://www.chadis.com/site/. Accessed 8 Nov 2020.

29. Howard BJ, Sturner R. Use of an online clinical process support as an aid to identification and management of developmental and mental health problems. Curr Dev Disord Rep. 2017;4(4):108-17.

30. Sturner R, Howard B, Bergmann P, Morrel T, Andon A, Marks D, Rao P, Landa R. Autism screening with online decision support by primary care pediatricians aided by M-CHAT/F. Pediatrics. 2016;138(3):e20153036. https://doi.org/10.1542/peds.2015-3036.

31. Squires J, Bricker D, Potter L. Revision of a parent-completed developmental screening tool: ages and stages questionnaires. J Pediatr Psychol. 1997:22(3):313-28. https://doi.org/10.1093/jpepsy/22.3.313.

32. Lyster R, Gotham K, Guthrie W, Coffing M, Petrak R, Pierce K, Bishop S, Esler A, Hus V, Oti R, Richler J, Risi S, Lord C. The autism diagnostic observation schedule-toddler module: a new module of a standardized diagnostic measure for autism spectrum disorders. J Autism Dev Disord. 2009:39(9):1305-20.

33. Mullen EM. The mullen scales of early learning. Circle Pines: AGS American Guidance Service Inc.; 1995

34. Filipek PA, Accardo PJ, Baranek GT, Cook EH Jr, Dawson G, Gordon B, et al. The screening and diagnosis of autistic spectrum disorders. J Autism Dev Disord. 1999;29(6):439-84

35. American Psychiatric Association. Diagnostic and statistical manual of mental disorders. 5th ed. Arlington: American Psychiatric Publishing; 2013.

36. Ringwalt, S. (Comp.). Summary table of states' and territories' definitions of/criteria for IDEA Part C eligibility (2015). http://ectacenter.org/ pdfs/ topics/earlyid/partc_elig_table.pdf.

37. Schuirmann DA. A comparison of the two one-sided tests procedure and the power approach for assessing the equivalence of average bioavailability. J Pharmacokinet Biopharm. 1987;15:657-80.

38. Dinno A. 2017. tost: Two one-sided tests for equivalence. Stata software package. https://www.alexisdinno.com/stata/tost.html

39. Youden WJ. Index for rating diagnostic tests. Cancer. 1950:3:32-5.

40. Schisterman EF, Perkins NJ, Liu A, Bondell H. Optimal cutpoint and its corresponding Youden Index to discriminate individuals using pooled blood samples. Epidemiology. 2005;16(1):73-81.

41. Robins DL. How do we determine the utility of screening tools? Autism. 2020:24(2):271-3. https://doi.org/10.1177/1362361319894170.

42. Sturner R, Howard B J, Bergmann P Stewart L, Afarian T. Comparison of autism screening in younger and older toddlers. J. Autism Relat Disord. 2017; P 1-9. https://doi.org/10.1007/s10803-017-3230-1

43. American Academy of Pediatrics, Addressing Mental Health Concerns in Primary Care: A Clinician's Toolkit. 2010, Revised January 2012.

44. Sturner R, Bergman P, Howard B, Bet K, Stewart L, Attar S. A Toddler adaptive development and autism screen (TADAS) efficiently improves Identification at the 18-month visit presented at the society for developmental and behavioral pediatrics. 2019; Washington, DC

45. Allison C, Matthews FE, Ruta L, Pasco G, Soufer R, Brayne C, Charman T, Baron-Cohen S. Quantitative checklist for autism in toddlers (Q-CHAT).
A population screening study with follow-up: the case for multiple time-point screening for autism. BMJ Paediatr Open. 2021;5(1):e000700. https://doi.org/10.1136/bmjpo-2020-000700

46. Cilia F, Carette R, Elbattah M, Dequen G, Guérin JL, Bosche J, Vandromme $\mathrm{L}$, Le Driant B. Computer-aided screening of autism spectrum disorder: eye-tracking study using data visualization and deep learning. JMIR Hum Factors. 2021:8(4):e27706. https://doi.org/10.2196/27706.

47. Havdahl KA, Bishop SL, Surén P, Øyen AS, Lord C, Pickles A, von Tetzchner S, Schjølberg S, Gunnes N, Hornig M, Lipkin WI, Susser E, Bresnahan M, Magnus P, Stenberg N, Reichborn-Kjennerud T, Stoltenberg C. The influence of parental concern on the utility of autism diagnostic instruments. Autism Res. 2017;10(10):1672-86. https://doi.org/10.1002/aur.1817.

\section{Publisher's Note}

Springer Nature remains neutral with regard to jurisdictional claims in published maps and institutional affiliations.

Ready to submit your research? Choose BMC and benefit from

- fast, convenient online submission

- thorough peer review by experienced researchers in your field

- rapid publication on acceptance

- support for research data, including large and complex data types

- gold Open Access which fosters wider collaboration and increased citations

- maximum visibility for your research: over 100M website views per year

At BMC, research is always in progress.

Learn more biomedcentral.com/submissions 